\title{
Development of stingless beekeeping projects in Malaysia
}

\author{
Mohd Mansor Ismail ${ }^{1, *}$ and Wan Iryani Wan Ismail $^{2}$ \\ ${ }^{1}$ Institute of Agricultural and Food Policy Studies, Universiti Putra Malaysia, Putra Infoport, Jalan \\ Kajang-Puchong 43400 UPM Serdang, Selangor, Malaysia \\ ${ }^{2}$ School of Fundamental Science, Universiti Malaysia Terengganu, 23100 Kuala Terengganu, \\ Terengganu, Malaysia
}

\begin{abstract}
Malaysia is in need of new high income project to meet the targeted high income nation by 2020. One such potential project in agriculture is stingless beekeeping. The project could supplement the existing beekeeping projects from Apis spp. such as Apiscerana and Apis mellifera in terms of honey production and pollination services. The introduction of stingless beekeeping in 2004 by MARDI was expected to provide new alternative species that was free from diseases and required simple farm management practices where adopters can operate the project as a part time job. The remaining labour hours can be used to earn off farm income. The project alone could generate a monthly income of up to RM5000 for the adopters with available capital and land, and this will enhance additional income and dietary consumption of the stingless bee products. The project is hypothesized to provide positive relationship with income and nutritional quality. For those farmers with land, government assistance is needed in providing cheaper credit to purchase stingless bee colonies which are the major portion of initial investment. In summary, the project is expected to reduce rural and urban poverty and generate a new source of wealth to private investors in Malaysia.
\end{abstract}

\section{Introduction}

Beekeeping has long been ignored by many developing countries as a source of additional income and foreign exchange. The industry has started as early as 1980s. Two main commercial species in Malaysia are Apiscerana (local bees) and Apismellifera (imported bees). But this species was plagued with diseases and was easily attacked by birds, pests and mites. The stingless bees of Trigona spp. is a new beekeeping activity that could complement natural honey production and pollination services. The aim of this study is to justify the development of stingless beekeeping in Malaysia. The basic valuation of the project mainly based on previous study on the feasibility of stingless bee farming, financially and economically. The financial study will provide the return on investment of stingless beekeeping project.

\footnotetext{
*Corresponding author: $\underline{\text { mkk@upm.edu.my }}$
} 


\section{Honey trade}

With plentiful nectar resources, surprisingly, Malaysia produces a paltry estimate of less than $5 \%$ (98mt /year) of her honey needs in 2000 but the country manages to increase its self-sufficiency level to $284 \%$ in 2010 (Table 1). This is a great achievement for the beekeeping industry and for Malaysia as a whole. According to [1] there are more than 700 stingless beekeepers in Malaysia, consisting 58, 593 colonies. The honey production of this stingless bee was estimated at $138,580.71 \mathrm{~kg}$ amounted RM 16, 988, 308. But, the country still imports its honey from abroad, which is reflected in prolong honey trade deficit after 2010 (Figure 1), mainly for industrial uses. The rest of the honey industrial requirement and for re-export purposes are imported from the temperate countries such as Australia and New Zealand. Imported honeys from China and Iran are much cheaper than the local honey but Malaysian prefers local honey [2]. This is reflected in the premium prices of all local honey (Apis and Trigona spp.) sold in Malaysia.

Malaysia imported low price honey for industrial use and exported high price honey for table consumption. In industry, honey is mainly used as ingredients or sweetener or additives in the confectionary, bakery, medicinal and pharmaceutical industries. One of the major honey exporters in the country is Summer Pacific Sdn. Bhd. located in Bintulu, Sarawak. The company produces about $100 \mathrm{mt}$ of Acacia honey every month. Unlike in Europe and the America, Malaysians, especially the Malays, consumed honey mainly for medicinal in nature, rather than as food supplements and, that is why, the per capita consumption in Malaysia is very low (estimated about $100 \mathrm{~g} /$ year).

Table 1. Export, import and balance trade of honey in Malaysia, 2000 - 2015.

\begin{tabular}{|l|r|r|r|r|r|r|}
\hline \multirow{2}{*}{ Year } & \multicolumn{2}{|c|}{ Export } & \multicolumn{2}{c|}{ Import } & \multicolumn{2}{c|}{ Balance of Trade } \\
\cline { 2 - 7 } & $\begin{array}{c}\text { Quantity } \\
\text { (Ton) }\end{array}$ & $\begin{array}{c}\text { Trade } \\
\text { Value (US\$ } \\
\text { '000) }\end{array}$ & $\begin{array}{c}\text { Quantity } \\
\text { (mt) }\end{array}$ & $\begin{array}{c}\text { Trade } \\
\text { Value } \\
\text { (US\$ '000) }\end{array}$ & $\begin{array}{c}\text { Quantity } \\
\text { (mt) }\end{array}$ & $\begin{array}{c}\text { Trade Value } \\
\text { (US\$ '000) }\end{array}$ \\
\hline 2005 & 88.44 & 213.23 & $2,167.35$ & $4,058.36$ & $(2,078.91)$ & $(3,845.13)$ \\
\hline 2006 & 238.72 & 486.03 & $2,482.82$ & $4,246.53$ & $(2,244.10)$ & $(3,760.50)$ \\
\hline 2007 & $2,263.40$ & $3,387.17$ & $4,935.51$ & $6,781.79$ & $(2,672.11)$ & $(3,394.62)$ \\
\hline 2008 & $4,572.63$ & $7,223.92$ & $6,744.85$ & $8,016.33$ & $(2,172.22)$ & $(792.40)$ \\
\hline 2009 & $7,382.46$ & $10,826.25$ & $8,232.90$ & $9,340.22$ & $(850.44)$ & $1,486.03$ \\
\hline 2010 & $13,453.57$ & $14,445.94$ & $7,913.57$ & $9,491.50$ & $5,540.00$ & $4,954.44$ \\
\hline 2011 & $2,508.56$ & $6,934.71$ & $3,159.62$ & $13,672.35$ & $(651.06)$ & $(6,737.64)$ \\
\hline 2012 & $1,578.91$ & $4,946.04$ & $2,207.09$ & $14,319.65$ & $(628.18)$ & $(9,373.61)$ \\
\hline 2013 & 696.28 & $2,283.02$ & $1,783.79$ & $11,562.52$ & $(1,087.51)$ & $(9,279.50)$ \\
\hline 2014 & 801.88 & $3,199.47$ & $3,156.85$ & $11,810.79$ & $(2,354.98)$ & $(8,611.32)$ \\
\hline 2015 & $3,521.27$ & $5,592.28$ & $4,913.35$ & $14,022.56$ & $(1,392.08)$ & $(8,430.28)$ \\
\hline
\end{tabular}




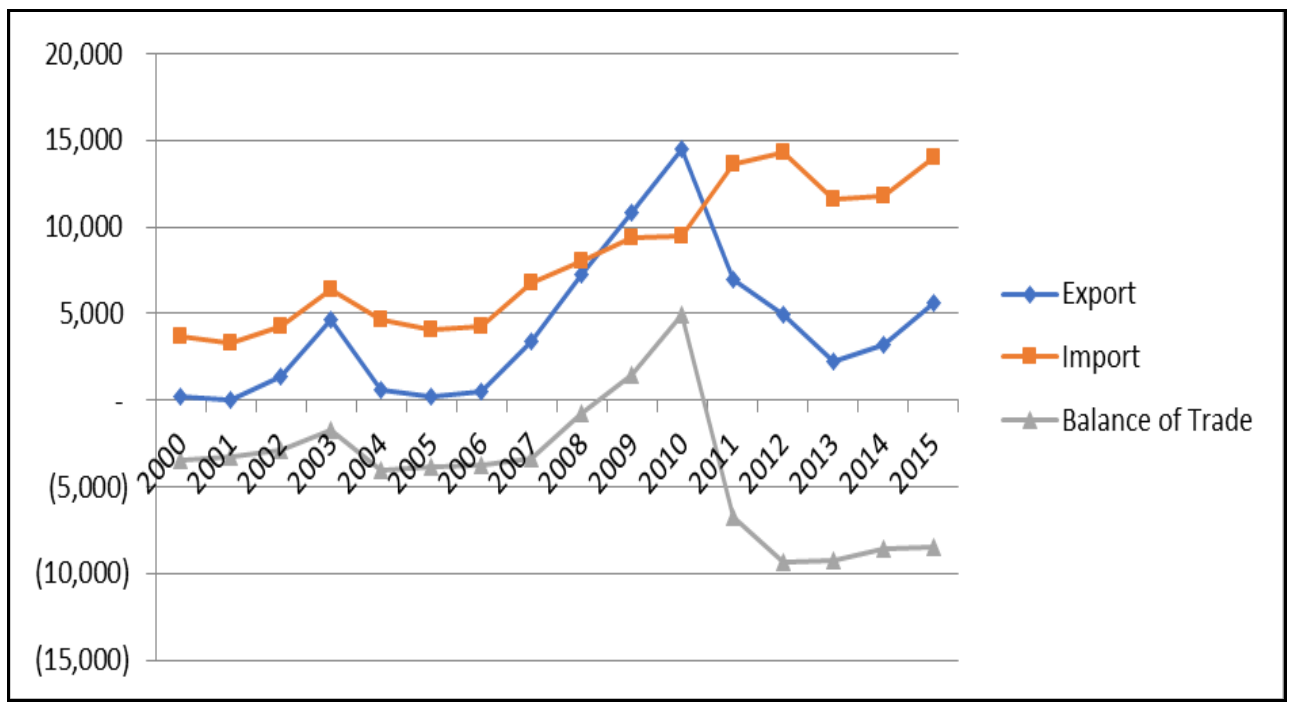

Fig. 1. Export, import and balance of trade for honey in Malaysia, 2000 - 2015 (US\$).

Note: USD1 is equivalent to RM4.00, 2018

\section{Natural factor endowment}

Malaysia possesses abundant natural resources that can sustain beekeeping activity producing bee products and by products that can be converted into high value-added health food, rich in both enzymatic and non-enzymatic antioxidants. Beekeeping plays a major role in socio-economic development and environmental conservation in Malaysia. It is a source of food (e.g. honey, pollen and brood), raw materials for various industries (e.g. beeswax candles and lubricants), medicine (honey, propolis, beeswax and bee venom) and as additional sources of income. It is estimated that the beekeeping industry is capable of generating millions of revenues each year from sales of bee products and by-products. It is an important income generating activity with high potential for improving incomes especially in the fruits and pineapple plantations and to rural farmers' bordering tropical forest reserves.

Johor, Selangor and Melaka and the bees are from the species of Apiscerana (the local bee) and, Apismellifera (the imported bee). There are about 700 beekeepers in 2010 (10000 colonies) compared to 946 in 1988 (7000 colonies). The yield from local bees is about 2-5 $\mathrm{kg}$ per year and $A$. mellifera (the imported bee) is expected to produce up to $50 \mathrm{~kg}$ per colony per year but prone to pests and diseases. The problems in rearing Acerana and $A$ mellifera prompted the industry to search for new species and found the Trigona spp. This species are quite diverse with estimated 50 species in Malaysia but only two species are expected to have commercialization potential. The research and development on the technical, financial and economic aspects of commercializing Trigona spp.is urgently needed to complement the existing production of natural honey in the industry.

Apiaries in Malaysia have aspects for improvement which can lead to higher yields and to a sustainable industry while exposing urgent technical problems. As a longer term objective, selections of new species like the Trigonaspp need to be started to obtain aspects like pests tolerant strains. By products such as beebread and propolisare still unexplored at the moment. Postharvest drying of honey and downstream processing are still remained untouched. All these technical aspects must be combined with financial and economic aspects before any suggestion to commercialize the stingless bee production. 
These aspects of beekeeping practices which we have identified in its technical perspective and futuristic vision can be improved via a larger coordinated programme involving collaborations among many disciplines of agriculture. It is expected that the improvement in research and development on the technical aspect of stingless beekeeping will eventually increase the production of local natural honey.

If natural honey production from Trigona spp. is feasible, then other by products can also be harvested such as beebread, propolis and pollination services, which are associated with the stingless beekeeping industry. The demand for honey and other by-products and services from the stingless beekeeping activities are to be explored and connected into the supply-chain concept of management. Other related industries, such as, probiotics (beverages), cosmetics (beauty soaps) and ecotourism can be linked and connected into a commercial critical-mass for the bee supply-chain network. The pollination services from honeybees in the USA is estimated to worth more than USD \$ 200 billion annually and it worth more than the honey production. No estimates are available for Malaysia at the moment. The potential of Trigonaspp.is enormous and what is urgently needed is the research on technical and financial feasibility of this activity and if the production systems possess comparative advantage, the Trigona farming is internationally competitive meaning the natural honey from Trigona spp. can be one of the Malaysia's export items in the future.

\section{Profitability}

In order for an industry to be sustainable, a project must be consistently profitable. Without profit, any companies will have to exit the industry. Since there are no technological constraints, any farmers can participate in stingless beekeeping. All they need is to follow a short course in stingless beekeeping that is organized by many research entities including private sectors, government agencies and University Putra Malaysia. A standard return on investment is presented in Table 2.

Table 2. Benchmark of Return on Investment (ROI) for 200 stingless bee colonies.

\begin{tabular}{|c|c|c|}
\hline Items & $\mathbf{R M}$ & $\mathbf{R M}$ \\
\hline Tax & $0 \%$ & $25 \%$ \\
Revenue & $64,800.00$ & $6,4800.00$ \\
Cost & $1,800.00$ & $1,800.00$ \\
Depreciation & $1,280.00$ & $1,280.00$ \\
EBT & $61,720.00$ & $61,720.00$ \\
Tax & 0.00 & $15,430.00$ \\
EAT & $61,720.00$ & $46,290.00$ \\
Monthly Income & $\mathbf{5 , 1 4 3 . 3 3}$ & $\mathbf{3 , 8 5 7 . 5 0}$ \\
Monthly Cash Flow & $5,250.00$ & $3,964.17$ \\
Total Investment & 86,400 & 86,400 \\
ROI & $\mathbf{7 1 . 4 4 \%}$ & $\mathbf{5 3 . 5 8 \%}$ \\
\hline
\end{tabular}

The Stingless beekeeping project can be considered as a high income project since it can provide the participant with more than RM5000 income per month (with zero tax). More incentives are also given by the Malaysian government in the promotion of food production. 


\section{Conclusion}

Stingless beekeeping projects are a new venture in beekeeping in Malaysia. Since the beekeeping management in Apis spp. is plagued with many farm management issues, the stingless beekeeping is preferred currently. The project is expected to provide more than $70 \%$ return on investment and a monthly income of more than RM5000. This is in line with the government intention of increasing the number of high impact agriculture project to the people. The stingless beekeeping project can be treated as a potential commercial project or as a rural and urban poverty eradication project in Malaysia.

\section{Acknowledgements}

The authors thankfully acknowledge the financial support received from the MOE RACE research grant.

\section{References}

1. Department of Agriculture, Putrajaya. Statistics of Stingless Beekeepers in Malaysia. Unpublished Report. Putrajaya, Malaysia, (2017)

2. M. Mansor. Honey marketing in Malaysia. Agricultural Marketing Issues of Selected. Commodities, Editor Fatimah Mohamed Arshad and Amin Mahir Abdullah, (2012) 